Document downloaded from:

http://hdl.handle.net/10251/167877

This paper must be cited as:

Galindo, J.; Tiseira, A.; García-Cuevas González, LM.; Hervás-Gómez, N. (2021). Experimental approach for the analysis of the flow behaviour in the stator of a real centripetal turbine. International Journal of Engine Research. 22(6):2010-2020. https://doi.org/10.1177/1468087420916281

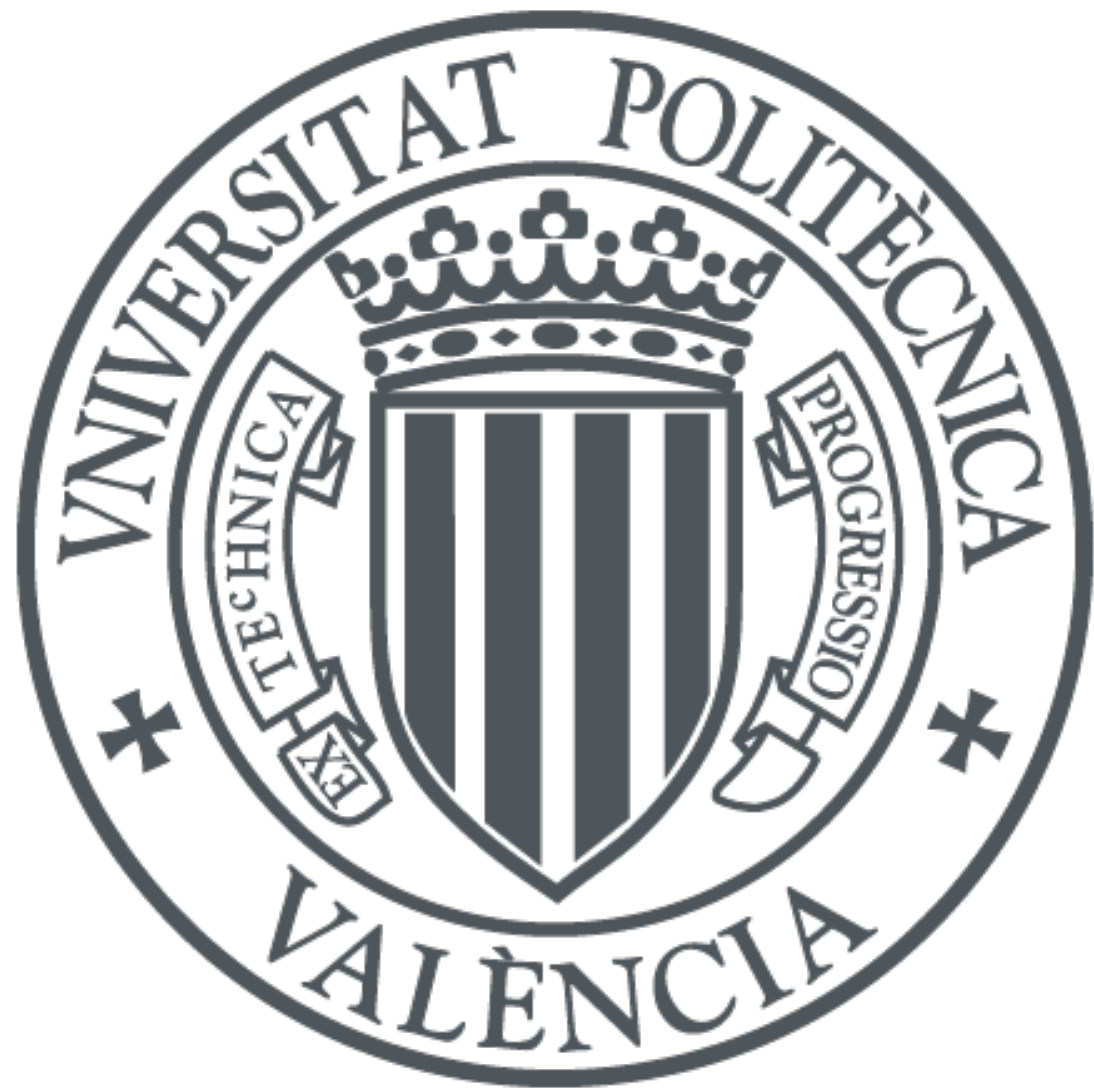

The final publication is available at

https://doi.org/10.1177/1468087420916281

Copyright SAGE Publications

Additional Information

This is the author's version of a work that was accepted for publication in International Journal of Engine Research. Changes resulting from the publishing process, such as peer review, editing, corrections, structural formatting, and other quality control mechanisms may not be reflected in this document. Changes may have been made to this work since it was submitted for publication. A definitive version was subsequently published as https://doi.org/10.1177/1468087420916281 


\title{
Experimental approach for the analysis of the flow behaviour in the stator of a real centripetal turbine.
}

\author{
J.Galindo, A.Tiseira, L.M. García-Cuevas, N. Hervás
}

CMT-Motores Térmicos, Universitat Politècnica de València, Spain

\begin{abstract}
During normal operation, radial turbines may work in off-design conditions. Off-design conditions may be characterised by very low expansion ratios, very high expansion ratios, very low rotational speeds or very high rotational speeds. All of these cases are difficult to characterise experimentally due to high experimental uncertainties or a lack of capabilities in the system feeding pressurised air to the turbine. Also, CFD simulations of these operating points can be not accurate enough in due to high turbulence effects, flow detachment and shock wave generation. With a lack of high-quality data to fit the reduced order turbine models used in zero- and onedimensional engine simulations, there are big uncertainties associated to their results in offdesign conditions. This work develops an experimental facility able to characterise the internal flow of radial turbine stators in terms of pressure and velocity fields at off-design and regular working conditions. The facility consists of an upscaled model of a radial turbine volute and stator fed with air in pressure- and temperature-controlled conditions, so different sensors can be used inside it with the least amount of flow disturbance. The different restrictions considered in the design of the upscaled model are presented, and their effects in the final experimental apparatus capabilities are discussed. A preliminary comparison between CFD simulations and experimental data shows encouraging results.
\end{abstract}

\section{Keywords}

Radial turbine, scaled volute -stator turbine, variable geometry turbine, experimental facility, CFD simulation, fluid measurement.

Corresponding author:

Natalia Hervás Gómez, CMT - Motores Térmicos Universitat Politècnica de València, Camino de Vera s/n, 46022 Valencia, Spain

Email: nahergme@mot.upv.es

\section{Introduction}

Nowadays, turbocharging is used regularly in different diesel and gasoline engines that are found in the automotive market. It is also a key system in the development of new engines with smaller or optimal sizes prepared for optimal consumption, low level of pollutants and even coupled to other systems such as electric engines. This trend is known as downsizing and rightsizing [1], [2] and an important part of the current research on internal combustion engines (ICE) in automotive focuses on optimising the turbocharging system. Apart from improving the performance and the 
fuel economy of new ICEs, and due to society concerns and the current legal framework, the focus is put in reducing their pollutant and greenhouse gases emissions [3], where better turbocharging is of capital importance.

In order to perform the matching between the turbocharger and the engine, the former needs to be characterised in terms of different performance parameters. This characterisation can be made experimentally or computationally by means of computational fluid dynamics (CFD) codes, and requires a lot of resources. The use of reduced order models able to interpolate and extrapolate the turbocharger performance parameters can greatly reduce the characterisation effort, so it is favoured by the industry.

Turbocharging models are increasingly useful and have been gradually improved thanks to the provision of experimental information. One example is the development of the one-dimensional turbine model developed by Payri et al. [4] in the CMT University Institute at the Universitat Politècnica de València for the main adiabatic performance phenomena of the turbine such as its instantaneous efficiency or instantaneous mass flow. Other example could be the contribution carried out by Macek et al [5] where developed a 1D model which intends to represent the turbine behaviour under unsteady flow conditions.

Along with the one-dimensional simulations, other tools have been coupled such as conjugate heat transfer models [6]-[9]. Finally, great advances have been made in obtaining values of mechanical losses for different points of operation [10], [11]. Therefore, using a one-dimensional model of supercharging, today dynamics of mass flow, heat transfer and mechanical losses can be calculated with acceptable precision. However, greater demands on the accuracy of the calculation cause the supercharging model to continue its development, due to the gradual changes in geometry suffered by these systems as a result of the continuous evolution.

To improve these tools, nowadays, one of the most used ways is based on characterising and analysing the flow behaviour at each stage of the turbine using CFD calculation models. Threedimensional and detailed-geometry effects are naturally taken into account, and the simulations can be performed with both steady-state and pulsating boundary conditions [12]-[14].

Another application that is currently on the rise is the use of reversible pump turbines in pumped hydro energy storage plant. The operation of these systems suffers from great instability problems, pressure fluctuations and severe vibrations. One of the physical origins of the problems described above is the rotating stall phenomenon generated at off-design conditions in generation mode [15]. Although CFD simulations are a valuable tool for analysing the flow behaviour and the turbine performance in a wide range of operating conditions, the accuracy of their results can degrade in off-design conditions. Experimental data is needed in order to validate CFD simulations in any case but, due to this loss of accuracy, it is extremely valuable in off-design operation such as very low or very high-pressure ratios or very low or very high rotational speeds. In these conditions, phenomena such as unsteady flow detachment and attachment, thick wakes or even unsteady shock waves decrease the accuracy of typical Reynolds-averaged Navier-Stokes equations (RANS) and unsteady RANS (URANS) simulations. Although it is possible to use higher-fidelity simulations, such as detached eddy simulations (DES) or large eddy simulations (LES) tend to be too computationally-expensive to be widely used in industrial applications.

Nevertheless, and usually, the internal flow cannot be compared with any experimental data. In this context, it is only possible to compare, in general terms, the parameters measured downstream and upstream of the turbine, which are summarised in the pressure, temperature and flow rate [16]. Moreover, reduced order turbine models normally use an equivalent nozzle model or assume same flow conditions at different turbine regions in order to simplify the problem [17]. In general, the research works with 3D models are interesting because they give a notion of the internal behaviour of the flow and can be used to improve reduced order models, but the authors 
of this manuscript, have not found any research work dedicated to the experimental internal flow measurement in small centripetal turbines, as those commonly used in the turbocharging system in ICE for ground transport. In order to fill this gap and to provide a useful tool for CFD and reduced order models validation as well as new geometry designs, an experimental facility has been developed in this work.

This article explains the development of an experimental facility with an upscaled turbine model that allows the characterisation of the internal flow in steady state and unsteady conditions. The general considerations needed to design the upscaled turbine model are presented first. Secondly, details about the final experimental apparatus are presented. Then, a proof-of-concept experimental campaign is shown, and CFD simulations of the same conditions are presented. Finally, the results are compared and conclusions are drawn.

\section{General considerations for upscaled model design}

As it has been said before, the off-design operation is characterised by very low or very highpressure ratios. The upscaled model has not got rotor so the case at very low or very high rotational speed are not taken in account. Each one of the off-design operation situations leads to different problem conditions that must be explained:

\section{Very low-pressure ratios}

The situations at very low-pressure ratios are characterised by low mass flow and velocity hence, the Mach and Reynolds numbers are low too. To have a small Reynolds number means that the viscous forces are important. Using Schilichting's approach [18] it is calculated that the percentage of the channel between the blades occupied by the boundary layer is around $20 \%$. In this case, if we want the results of the upscaled model to be representative we must keep the Reynolds number from the real turbine.

Very high-pressure ratios

This is the opposite situation, characterised by high mass flow and velocity therefore, the Mach and Reynolds numbers are large. Facing the previous situation, in this case, if we want the results of the upscaled model to be representative we must keep the Mach number constant which is equivalent to maintaining the dimensionless flow from the real turbine.

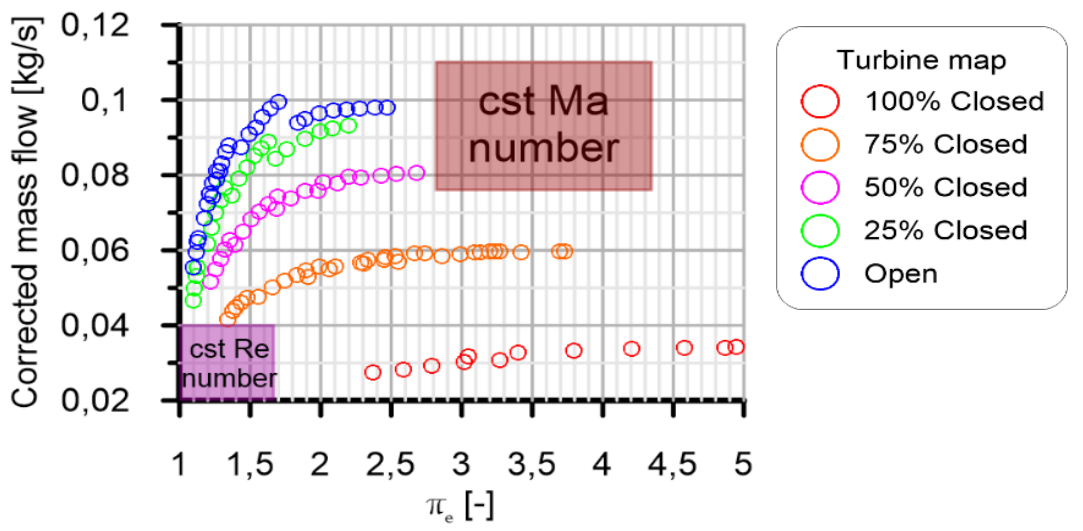

Figure 1. Generic turbine map with the situations explained before.

The ideal plan would be in which the Reynolds and Mach numbers could be controlled simultaneously but, to achieve this, pressures and temperatures impossible to reach in a standard test bench are needed. The characteristics of the test bench used are maximum mass flow of 1200 $\mathrm{kg} / \mathrm{h}$ and maximum relative pressure around $400 \mathrm{mbar}$. These limits indicate that it is infeasible to reach very high-pressure ratios thus, to keep constant Reynolds number is the choice selected. 
At very off-design conditions and keeping the Reynolds number constant, the velocity is low. This means that the Mach number must be low as well. In this case the Mach is going to be lower than 0.3 so that no compressible effects appear. Next, we will study the scale needed in the model so that the maximum local Mach between the stator blades is less than 0.3. Using the same generic turbine map of Figure 1, the maximum Mach between the blades is the one represented in the Figure 2.

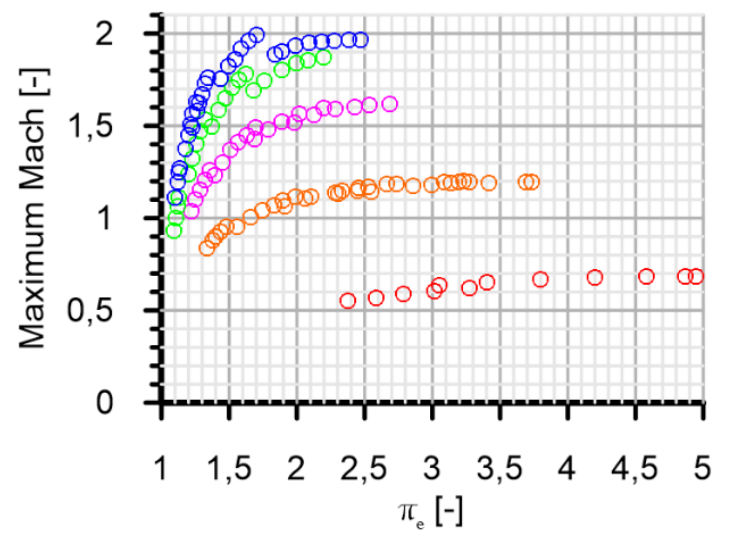

Figure 2. Maximum Mach number in a generic turbine.

It can be observed that the maximum Mach with 1:1 scale factor is clearly compressible. If the scale factor increases, the maximum Mach number decreases following the relation:

$$
M a_{\text {max }}=\dot{m}^{*} \cdot \frac{\sqrt{T_{\text {ref }}}}{P_{\text {ref }}} \cdot \sqrt{\frac{R}{\gamma}} \cdot \frac{1}{D_{\text {rot }} \cdot \pi \cdot h_{s t}}
$$

With all this information it is possible to find the minimum scale factor that satisfies the Mach number condition. In the next figure it is clear that the suitable scale factor is $3: 1$.

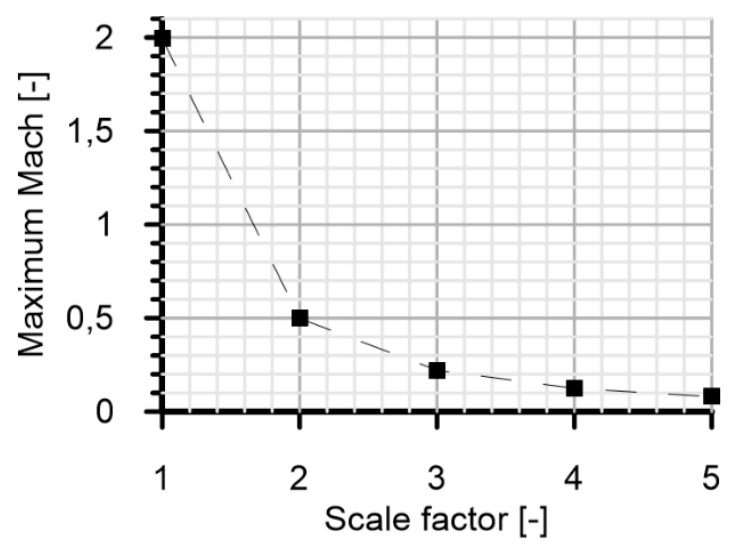

Figure 3. Maximum Mach number vs. model scale factor.

Having the scale factor and the study situation selected (keep Reynolds number constant for very low-pressure ratios), it is time to know if the upscaled model works at regular turbine operation range for, in the future, apply the very off-design conditions.

Three steps have defined the methodology presented in this work. The first introduce the hypothesis of fluid mechanic and unidimensional parameters to find the correlation between upscaled and real turbine. The other two, CFD calculation and experimental study, are presented below. Continuing, the theoretical study determines the viability of the upscaled experimental model. This process determines the operation range of the scaled turbine. Therefore, the procedure consists in realize an approximation of flow behaviour considering the Reynolds 
number ( $\mathrm{Re}$ ) and controlling the Mach number (Ma). These two parameters ensure the direct relationship between the real turbine and the scaled turbine. The first one allows to assure the same fluid behaviour in the scaled turbine and in the real turbine when the viscous forces are important. The second value determines the limits of the air mass flow through the stator channels in the scaled turbine.

As has been described, a theoretical study was carried out in order to know the mass flow conversion from real turbine to the scaled one. The Reynolds number equation was used to reproduce the fluid behaviour of a normal size turbine. This equation relates the inertial (or convective) and viscous forces present in a fluid.

$$
\operatorname{Re}(T)=\frac{c \cdot V(T) \cdot \rho(T)}{\mu(T)}
$$

The Reynolds number value depends on an important parameter, the temperature. For this reason, the Re parametric study was performed based on this variable, as can be seen in equation 2 .

The values required to calculate the Reynolds number of a real turbine were obtained from a CFD study at $50 \%$ closure of VGT and half-load operating point. Commonly, the turbocharger turbine, installed in a diesel or gasoline engine, is around this opening position.

Table 1. Geometric and air values to compute the Reynolds number.

\begin{tabular}{|l|l|}
\hline Chord & $0,0179 \mathrm{~m}$ \\
\hline Velocity & $127 \mathrm{~m} / \mathrm{s}$ \\
\hline Dynamic viscosity & $3,2 \cdot 10-5 \mathrm{~kg} / \mathrm{ms}$ \\
\hline Density & $1,22 \mathrm{~kg} / \mathrm{m3}$ \\
\hline Mass flow & $0,097 \mathrm{~kg} / \mathrm{s}$ \\
\hline
\end{tabular}

As a result of the previous values, the Reynolds number that was set to simulate the fluid characteristics in the scaled turbine, obtained from parameters shown in Table 1, has been $R e=$ 86760,25 . To begin with the extrapolation data, the Reynolds number obtained is maintained and the blade chord is modified by that of the upscaled turbine. The pressure has not been taken as parameter since the variation of this does not affect the mass flow as will be seen later. The purpose has been determining the velocity, with it, the mass flow required to reproduce the existing conditions inside a real turbocharger for a half-load operating point, and $50 \%$ closure of turbine stator. Therefore, the following lines comment the procedure:

- Calculate the density through the ideal gas equation

$$
p(T)=\rho(T) \cdot T \cdot R \rightarrow \rho(T)=\frac{p(T)}{T \cdot R}
$$

- The dynamic viscosity was estimated with the Sutherland equation, where the temperature, pressure and density were known.

$$
\mu(T)=\mu_{o} \cdot\left(\frac{T_{o}+C}{T+C}\right) \cdot\left(\frac{T}{T_{o}}\right)^{\frac{3}{2}}
$$

Where $\mu_{0}=18.27 \cdot 10^{-6} \mathrm{Nsm}^{-2}$ the reference dynamic viscosity and the reference temperature is $T_{0}=291.15 \mathrm{~K}$.

- The velocity was calculated from the Reynolds number equation. 


$$
V(T)=\frac{R e \cdot \mu(T)}{c \cdot \rho(T)}
$$

- Finally, when all the other variables were already calculated, the mass flow was obtained.

$$
\dot{m}(T)=\rho(T) \cdot A \cdot V(T)
$$

The values from scaled turbine employed for the following studies are resumed in the Table 2:

Table 2. Scaled turbine values.

\begin{tabular}{|l|l|}
\hline$r_{2 a}$ & $0,088 \mathrm{~m}$ \\
\hline$L_{T E}$ & $0,0276 \mathrm{~m}$ \\
\hline Chord & $0,0525 \mathrm{~m}$ \\
\hline Channel area & $5,14 \cdot 10^{-4} \mathrm{~m}^{2}$ \\
\hline Reynolds number & 86760,25 \\
\hline
\end{tabular}

These values were obtained using the methodology exposed in [17] by Serrano et al. The methodology has the capacity to estimate the geometrical throat section of the stator vanes based on VGT position and geometrical turbine parameters. The required metal angle $\left(\alpha_{2}{ }^{\text {metal }}\right)$ was calculated using a linear relation between stator vanes angle and VGT opening of three turbochargers with similar characteristics to that of the model.

With the intention of clarifying the meaning of the parameters that are observed in the figure 1a and following the criterion employed in [17], the station 2 is located at the stator outlet. The parameter $r$ is the distance between the rotor centre and the stator vanes axis of rotation $(2 a)$ or the stator outlet (2). Likewise, $L_{T E}$ is the distance between the stator blades axis of rotation and trailing edge.

a)

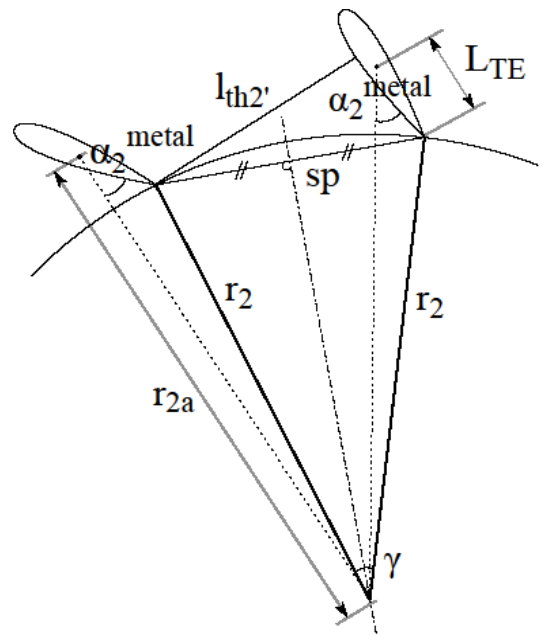

b)

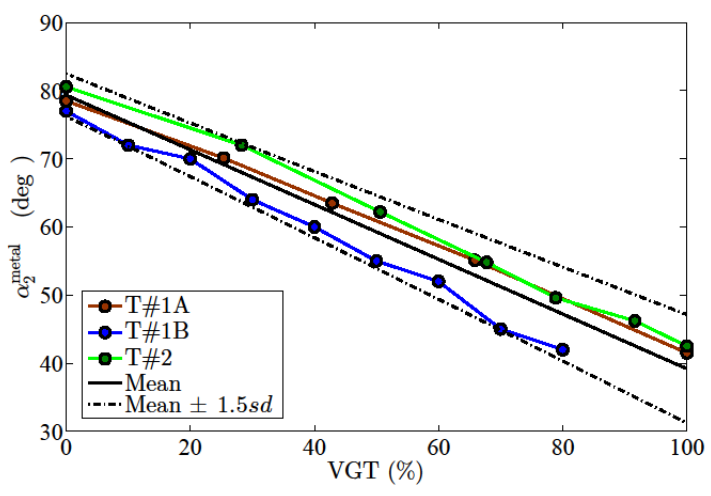

Figure 4. a) Geometrical relations of VGT stator vanes and b) linear relations between stator vanes angle and VGT opening.

The mass flow results obtained at different temperatures were the exposed in the Table 3:

Table 3. Scaled mass flow for half-load operating point.

\begin{tabular}{|c|c|c|c|}
\cline { 2 - 4 } \multicolumn{1}{c|}{} & \multicolumn{3}{c|}{$\dot{m}(\mathrm{~kg} / \mathrm{s})$} \\
\hline$T[\mathrm{~K}]$ & $p=1 \mathrm{~atm}$ & $p=1,5 \mathrm{~atm}$ & $p=2 \mathrm{~atm}$ \\
\hline 313 & 0,1805 & 0,1805 & 0,1805 \\
\hline 343 & 0,1936 & 0,1936 & 0,1936 \\
\hline
\end{tabular}


It is observed in the results that the variation of the pressure does not affect the mass flow if it is established that the Reynolds number must be constant

\section{Flow Velocity Study}

The mass flow obtained in the previous section corresponds to a specific turbine operating point. However, the turbine is able to operate in a wide range condition.

The value of the mass flow obtained in the case of the real turbine is taken again and superimposed on the map of a similar characteristics turbine Figure 5. It is appreciated that this point is located, more or less, at the middle of the turbine operating range. The VGT position with filled symbols corresponds to $50 \%$ closure of turbine stator.

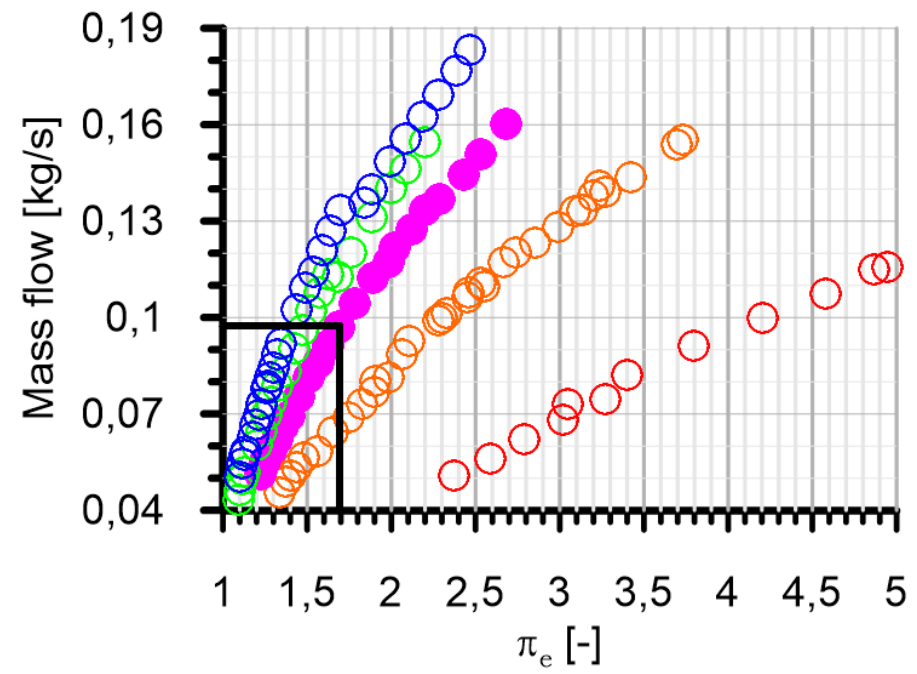

Figure 5. Scaled operating point in a real turbine map.

To have a first approximation of the range of mass flow with which the model should work, it was decided to choose the lowest and highest real mass flow. Subsequently, with the new mass flows, it was carried out the conversion to the scaled turbine maintaining the corresponding Reynolds number. As in the previous case, this conversion was performed as a function of the temperature but not of the pressure since, as has been shown, this does not affect the mass flow. As the lower limit, the real mass flow of $0,06 \mathrm{~kg} / \mathrm{s}$ was selected. Doing exactly the same steps than the previous case, the results shown in Table 4 were obtained.

Table 4. Scaled mass flow for low-load operating point

\begin{tabular}{|c|c|c|c|c|}
\hline $\boldsymbol{T}[\mathrm{K}]$ & $\rho\left[\mathrm{kg} / \mathrm{m}^{3}\right]$ & $\mu\left[\mathrm{Ns} / \mathrm{m}^{2}\right]$ & $\boldsymbol{V}[\mathrm{m} / \mathrm{s}]$ & $\dot{\boldsymbol{m}}[\mathrm{kg} / \mathrm{s}]$ \\
\hline 313 & 1,117 & 0,00001918 & 18,014 & 0,114 \\
\hline 343 & 1,029 & 0,00002052 & 20,978 & 0,122 \\
\hline
\end{tabular}

As the upper limit, the real mass flow of $0,16 \mathrm{~kg} / \mathrm{s}$ was selected. The results for this case were the exposed in Table 5.

Table 5. Scaled mass flow for high-load operating point.

\begin{tabular}{|c|c|c|c|c|}
\hline $\boldsymbol{T}[\mathrm{K}]$ & $\rho\left[\mathrm{kg} / \mathrm{m}^{3}\right]$ & $\mu\left[\mathrm{Ns} / \mathrm{m}^{2}\right]$ & $\boldsymbol{V}[\mathrm{m} / \mathrm{s}]$ & $\boldsymbol{\boldsymbol { m }}[\mathrm{kg} / \mathrm{s}]$ \\
\hline 313 & 1,117 & 0,00001918 & 47,287 & 0,298 \\
\hline 343 & 1,029 & 0,00002052 & 55,068 & 0,320 \\
\hline
\end{tabular}


Based on all the results, it can be concluded that, for a VGT closed at $50 \%$, the range of mass flow with which the scaled model will be worked is between $0,114 \mathrm{~kg} / \mathrm{s}$ and $0,320 \mathrm{~kg} / \mathrm{s}$.

The Figure 6 summarize the process of extrapolate the real mass flow for the scaled turbine. The Figure 6a) shows the Reynolds number for each real mass flow from Figure 5. Then, to ensure the good extrapolation of the data to the scaled turbine, the Reynolds number is keeping constant and the new mass flow for the scaled turbine is calculated with the parameters of the new turbine.

a)

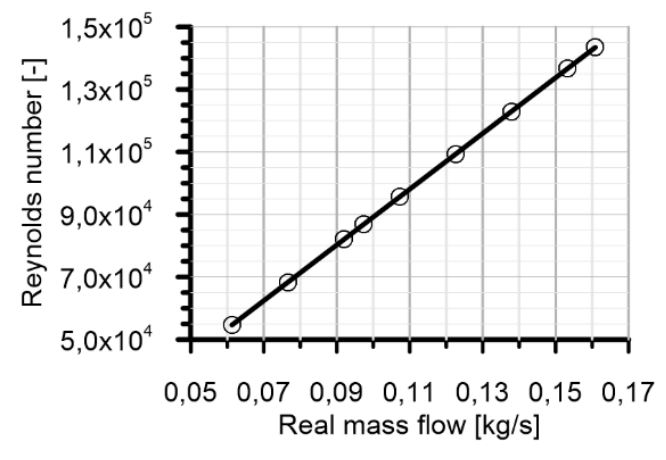

b)

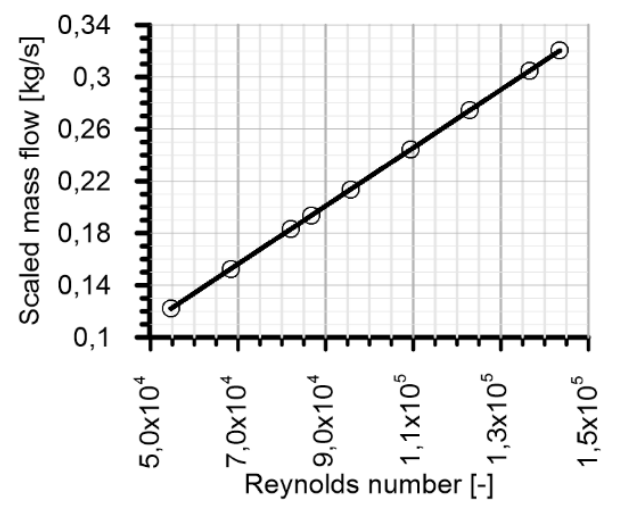

Figure 6 a) Reynolds number calculated through the real mass flow and b) scaled mass flow obtained keeping constant that Reynolds number

\section{Experimental Setup}

The theoretical study defines the minimum and maximum air mass flow value for different openings of the turbine stator at an experimental 3:1 scale. Therefore, the study solves the conversion of the real values of flow in the model of the turbine. This experimental work focuses on the volute and stator set, because the behaviour that the flow acquires between these stages will strongly affect the operation of the rotor. That is why the model to be used will represent the actual geometry of the volute and stator of a latest generation radial turbine at the scale that has been defined as acceptable for the measurement sensors employed to characterize the behaviour of the fluid. The sensors have been located at the entrance and exit of the volute and at the entrance and exit of the stator channel. An important requirement in the design of the scale turbine is that the stator blades must have different positions simulating the movement of the variable geometry turbine (VGT). Hence, the model has interchangeable discs with fixed positions. Every one of the discs represent different opening angles of the VGT. However, only the results corresponding to the 50\% opening of the VGT will be shown in this paper. Each element of the turbine model has been assembled by fixing screws and joint between pieces has been designed to avoid any air leakage.

The objective of the work is focused on characterizing the flow inside a radial turbine in the volute and stator set by printing the internal channel of the volute and the stator channels (VGT). The complete set of the turbine model consists of the following bodies, once completed and optimized its design: volute - blades plate - central cavity and outlet channel.

In Figure 7, the design of the centripetal turbine with volute and stator is shown. On the right of the same figure it is possible to see the scaled turbine assembled. Five are the VGT openings built (fully closed, 25\%, 50\%, 75\% and 100\% open). Each opening has been measured with a displacement sensor placed in the real turbine attached to the displacement axis of the blades crown. 

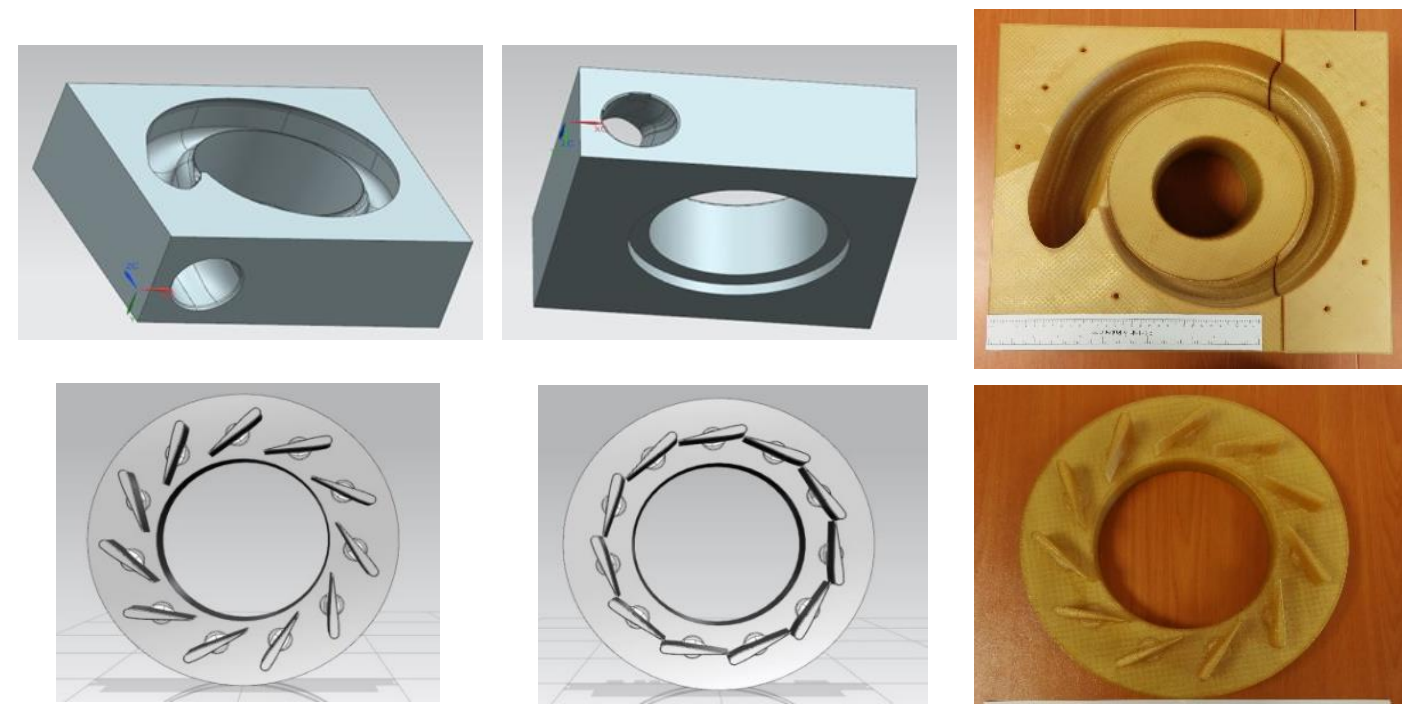

Figure 7. Design and construction of the internal flow characterization system based from a real turbine.

The experimental model turbine has been placed in a gas stand bench for its characterization. The instrumentation has been placed in different stator channels for do not interfere the inlet pitot tube (5-hole) in the measurement of the outlet pitot tube (5-hole). The placement has a position determined by the radial axis of the stator (longitudinal axis of the channel). At the same time, an internal mechanism for the relative position for each pitot has been devised. Outside the turbine it knowing the relative angle between the pitot and the longitudinal axis of the channel depending on the position of the blades of the VGT. In Figure 8 is shown the totally closed and hermetic experimental model turbine, located in the test bench.

In addition, it has a pressure value that conforms to the theoretical curve calculated for the experimental model turbine. The inlet and outlet ducts of the scale turbine are fully instrumented with pressure and temperature sensors to determine the operating point of the turbine (volute stator).

Once the model and the test bench are discussed, the experimental testing campaign is explained in the Table 6. As stated before, the control variables are the temperature and the mass flow. The temperatures were selected considering the limitations of the measurement sensors. On the other hand, the values of the mass flow were set according to the results obtained about a theoretical study. Further, it has been used to test the entire VGT at $50 \%$ position.

Table 6. Experimental testing campaign

\begin{tabular}{|c|c|c|}
\hline $\boldsymbol{T}[\mathrm{K}]$ & $\dot{\boldsymbol{m}}[\mathrm{kg} / \mathrm{s}]$ & Test number \\
\hline \multirow{3}{*}{313} & 0,111 & 1 \\
\cline { 2 - 3 } & 0,194 & 2 \\
\cline { 2 - 3 } & 0,305 & 3 \\
\hline \multirow{3}{*}{343} & 0,111 & 4 \\
\hline & 0,194 & 5 \\
\cline { 2 - 3 } & 0,305 & 6 \\
\hline
\end{tabular}




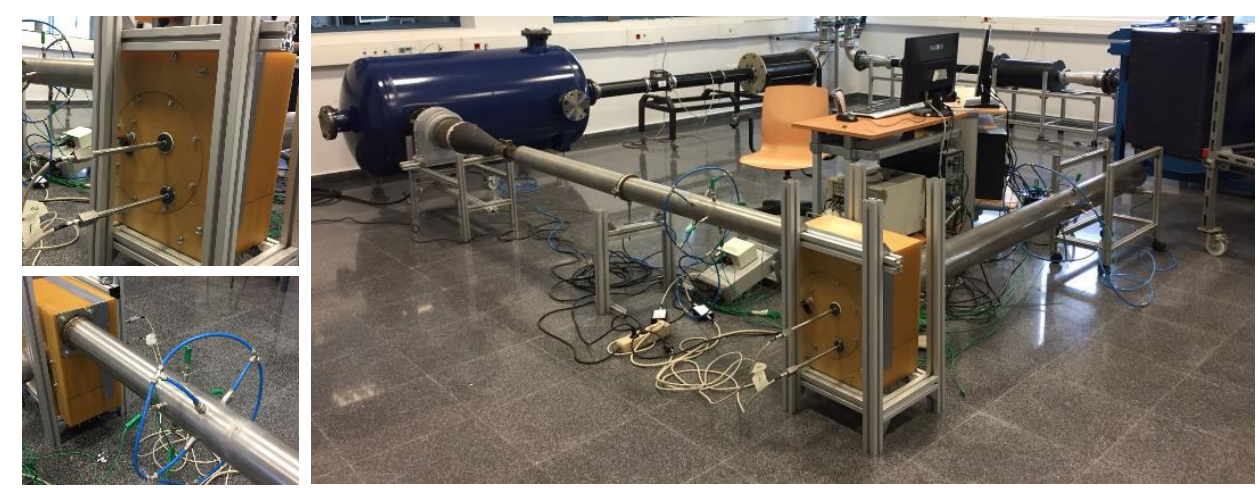

Figure 8. On the top left, the two pitot tubes. On the bottom left, the pressure and temperature sensors in the duct. On the right, the flow bench installation.

\section{Computational Study}

The computational study was performed using STAR CCM+. The Figure 9 shows a partial view of the volute - stator set used in this work. The computational domain included two zones not shown in the Figure 9: a straight duct, which are placed at the turbine outlet and a big volume, connected to the turbine outlet duct. The straight duct separates the outlet boundary condition from the turbine and the volume allows to represent the ambient conditions at the outlet.
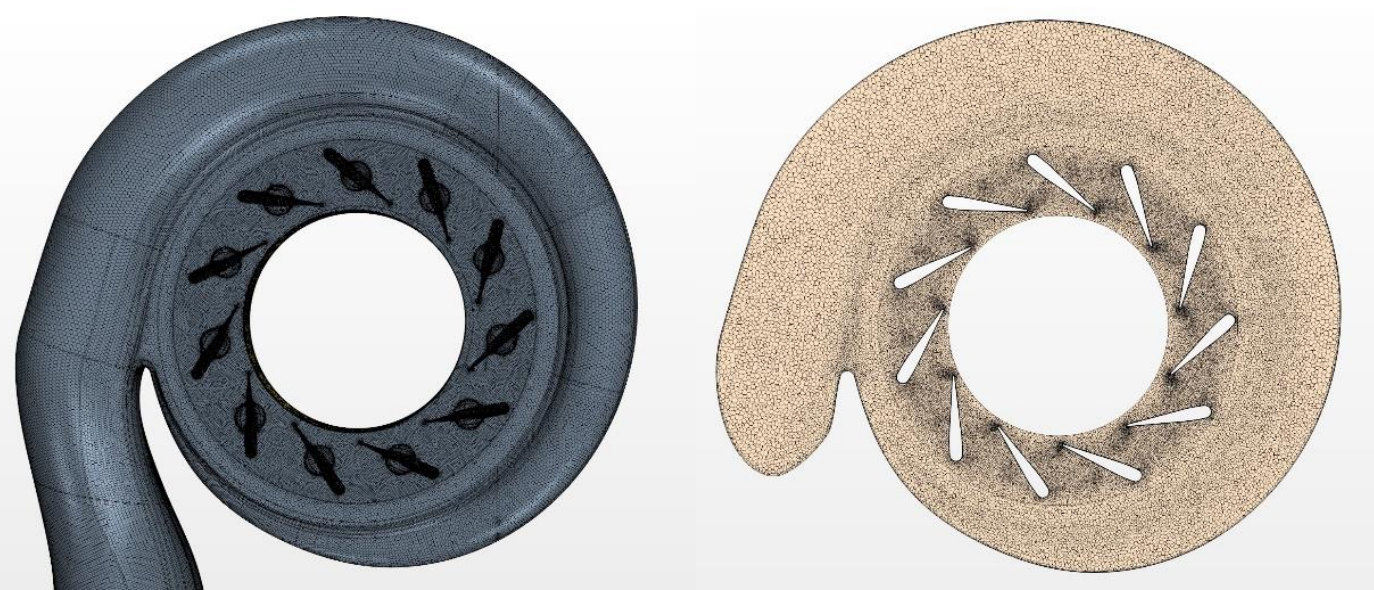

Figure 9. Turbine geometry and 3D computational mesh.

The model has not rotor. The absence of rotor causes that the outlet flow be rotational and, therefore, adhere to the walls of the outlet duct. For this reason, the output volume has been introduced whose boundary condition is the ambient pressure and allows, in case of backflow, that this returns to the system in the real conditions experimentally tested

\section{Mesh Information}

The 3D mesh used for the computations is shown in Figures 10 and 11. The main difficulty when it comes to real geometries is to achieve an adequate mesh. For this paper a non-conformal mesh made with polyhedral polygons was opted. In addition, the authors chosen the option of Prism Layer Mesh with the intention of improving the mesh in the boundary layer of the blades and in the gap between the blade and the volute, as can be seen in the Figures 10 and 11. 


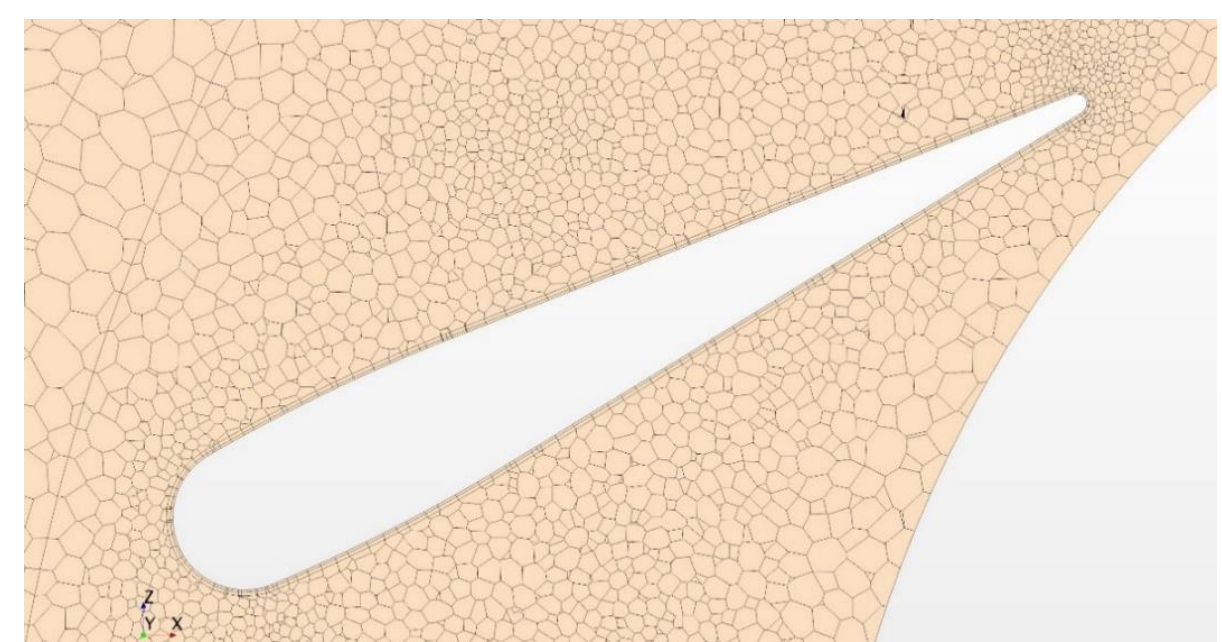

Figure 10. Mesh along a blade using Prism Layer Mesh.

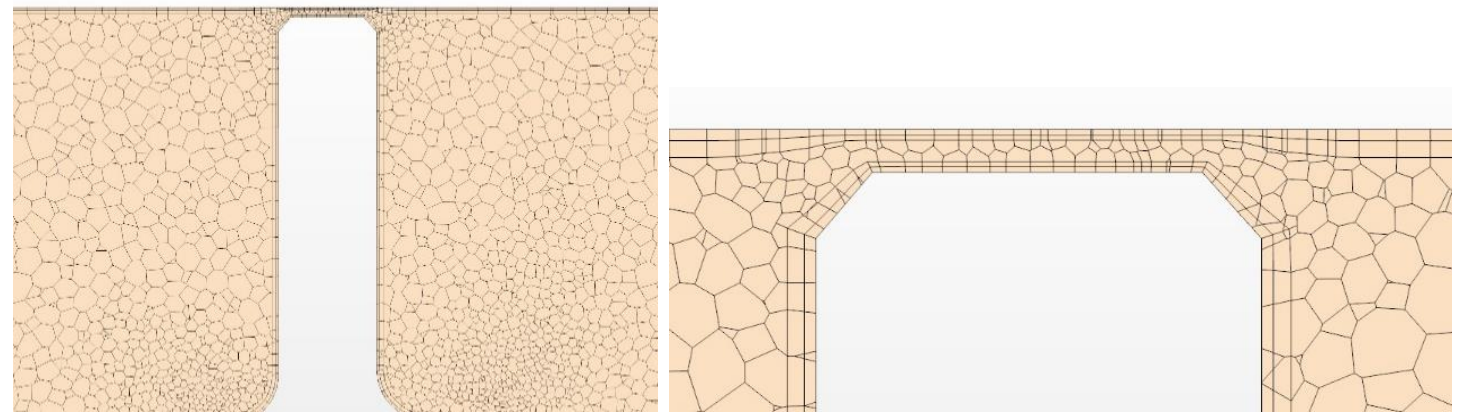

Figure 11. Detail of the mesh in the gap between the blade and the volute.

A numerical accuracy study was performed to evaluate the independence of the numerical results with the mesh size. This analysis has been done considering the average cell size in VGT and volute. Due the magnitude of the outlet volume, his average cell size is bigger than the rest of the system. The different computations for the mesh independence analysis have been performed keeping a constant mass flow rate $(0,305 \mathrm{~kg} / \mathrm{s})$ and temperature $(343 \mathrm{~K})$. The results are presented in Table 7.

Table 7. Mesh independence analysis.

\begin{tabular}{|c|c|c|c|c|c|c|}
\hline \multirow{2}{*}{ Mesh number } & \multirow{2}{*}{ Cells in the mesh } & \multirow{2}{*}{$\begin{array}{c}\text { Average cell } \\
\text { size }[\mathrm{mm}]\end{array}$} & \multicolumn{2}{|c|}{ Total pressure [Pa] } & \multicolumn{2}{c|}{ Velocity [m/s] } \\
\cline { 4 - 7 } & & Inlet & Outlet & Inlet & Outlet \\
\hline 1 & 4423526 & 2,5 & 105276,2 & 104879,8 & 44,84 & 79,20 \\
\hline 2 & 6911928 & 2,1 & 105495,8 & 105017,1 & 48,43 & 78,94 \\
\hline 3 & 8795791 & 1,9 & 105671,2 & 105444 & 49,50 & 80,90 \\
\hline
\end{tabular}

The difference found between the mesh 2 and 3 is about a $0.41 \%$ in the total pressure and less than $2.5 \%$ in the velocity. In addition, the difference in the average cell size is only the $0,2 \mathrm{~mm}$. On the other hand, the mesh cannot be as thin as Mesh 3 due to the computational resources and the long calculation time. For these reasons, the grid number 2 has been used.

\section{Case Configuration}

The segregated solver was used to perform a Reynolds-Averaged Navier-Stokes (RANS) with an SST $\kappa-\omega$ turbulence model, following the criteria found in the literature [19]. The RANS "main advantage is their good trade-off between computational cost and accuracy" [13]. The biggest advantage of the SST model is that it combines the robust and precise formulation of the 
$\kappa-\omega$ model [20] in the region close to the wall with the free-stream independence of the $\kappa-\varepsilon$ model [21] in the far field. The SST turbulence model is commonly used in many of the turbomachinery applications found in the literature as can be seen in [22]-[24]. These examples demonstrate the model's ability to reproduce the flow separation in a wide range operations condition.

In addition, manufacturers usually test the turbochargers following the standard procedure which consists of performing the tests under steady-flow conditions. The entire computational study was performed under steady-inflow conditions too. The boundary conditions applied were total temperature and mass flow rate at the inlet and static pressure at the outlet, in this case the big volume.

\section{Results Comparison}

As has been said before, numerical study was performed for different mass flow rate and temperature at the inlet. The mass flow rate was modified with the purpose of simulate an entire stator position of the turbine, specifically the $50 \%$ opening.

The parameters that the authors consider interesting to analysed in order to validate the new experimental methodology with the numerical study are the velocity, static pressure and total pressure as a function of the mass flow rate. These three parameters were measured at the inlet and outlet of different stator channels. Every test was done in steady flow conditions so, the time variation is not a relevant parameter.

The results shown below belong to the CFD modelling with 7 million cells for the $313 \mathrm{~K}$ and 343 $\mathrm{K}$ temperatures test. Table 8 presents the relative difference of the static and total pressure values between the experimental model and the CFD model. The comparison is made using the equation 7 where $\phi$ is a generic parameter.

$$
\epsilon_{\text {exp }}(\%)=\frac{\phi_{C F D}-\phi_{\text {exp }}}{\phi_{\text {exp }}} \cdot 100
$$

Table 8. Experimental and numerical relative difference.

\begin{tabular}{|c|c|c|c|c|c|}
\hline \multirow{2}{*}{$\boldsymbol{T}[\mathrm{K}]$} & \multirow{2}{*}{$\dot{\boldsymbol{m}}[\mathrm{kg} / \mathrm{s}]$} & \multicolumn{2}{|c|}{ Total pressure relative difference [\%] } & \multicolumn{2}{|c|}{ Static pressure relative difference [\%] } \\
\hline & & Inlet & Outlet & Inlet & Outlet \\
\hline \multirow{3}{*}{313} & 0,111 & $-0,81$ & $-0,71$ & $-0,72$ & $-0,52$ \\
\hline & 0,194 & $-1,54$ & $-1,31$ & $-1,64$ & $-2,53$ \\
\hline & 0,305 & $-3,46$ & $-3,10$ & $-3,67$ & $-3,54$ \\
\hline \multirow{3}{*}{343} & 0,111 & $-1,30$ & $-0,91$ & $-1,09$ & $-0,59$ \\
\hline & 0,194 & $-2,57$ & $-2,17$ & $-2,36$ & $-1,59$ \\
\hline & 0,305 & $-4,86$ & $-4,24$ & $-4,75$ & $-3,74$ \\
\hline
\end{tabular}

As can be seen in Table 8, the relative difference between the experimental and computational results do not exceed $5 \%$. On the other hand, comparing the values of velocity, at the inlet and outlet channel, among the experimental study and the CFD modelling, a similar tendency can be observed. 

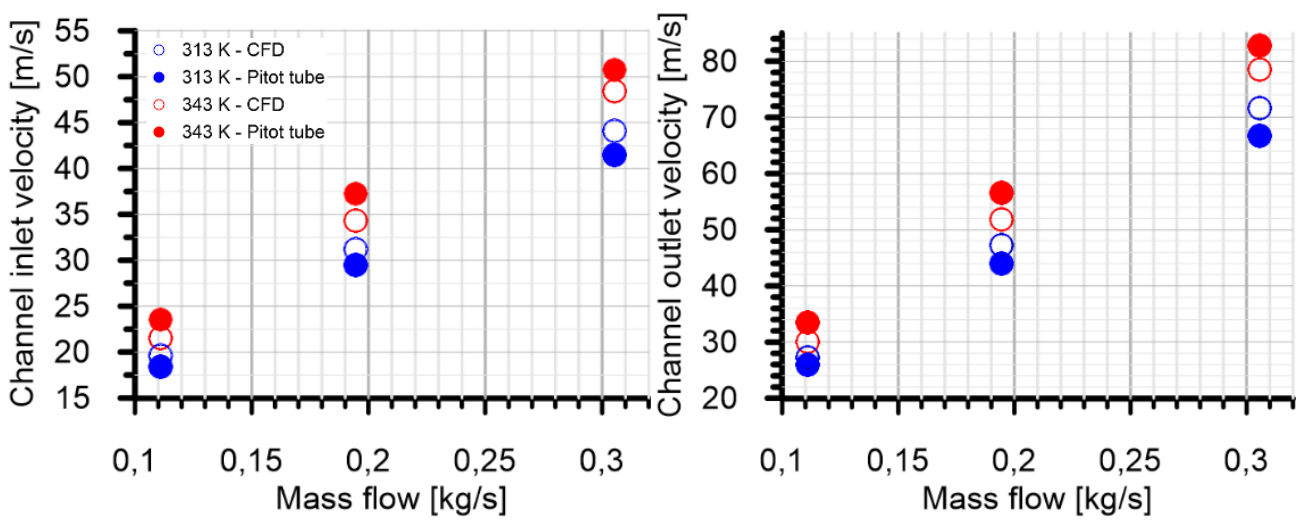

Figure 12. Channel inlet and outlet velocity magnitude vs. mass flow rate

Figure 12 present the inlet and outlet velocity magnitude as a function of the mass flow rate. If it is compared the results considering the temperatures, the velocity increases as the temperature grows, regardless of whether it is measured experimentally or computationally. Likewise, the stator channel inlet and outlet velocities are increase with the mass flow rate. The trend is similar in the experimental and CFD results. The slopes show good agreement between the experimental and computational studies. Both studies reveal a small value deviation between them. The Table 9 show a summarize about the relative difference in terms of growing velocity rate due the increment of air mass flow through the stator vanes channel.

Table 9. Velocity slope relative difference

\begin{tabular}{|c|c|c|}
\hline \multirow{2}{*}{$\begin{array}{c}\text { Temperature } \\
{[\mathrm{K}]}\end{array}$} & \multicolumn{2}{|c|}{$\begin{array}{c}\text { Velocity slope relative } \\
\text { difference [\%] }\end{array}$} \\
\cline { 2 - 3 } & Inlet & Outlet \\
\hline 313 & 5,7 & 8,1 \\
\hline 343 & 1,2 & 1,5 \\
\hline
\end{tabular}

The greatest deviations occur at low temperature. This is because the kinetic energy is lower in that case and the walls roughness of the turbine model affect more than at high temperature, with bigger kinetic energy.

\section{Summary/Conclusions}

This article describes a new methodology for the characterization of the internal flow in radial turbines under steady flow conditions for, in the future, to be able to do it in non-steady and offdesign conditions. The main objective has been to evaluate the fluid-dynamics at the inlet and outlet of the stator channel. The pressures and velocities measurements inside the stator have been carried out by using 5-hole pitot tubes. This experimental measurement methodology has been possible thanks to the creation of a scaled turbine, for this it was started with a real turbine. It has been demonstrated, by means of a theoretical study, the range of mass flow rate values necessaries to reproduce a complete turbine stator position, specifically the $50 \%$ opening.

The design of the turbine has also been studied using CFD modelling. This computational study has served as a basis for comparing the results obtained in the experimental part. Several tests have been implemented with different values of temperature and mass flow rate at the entrance of the volute. Comparing the results, similar values are obtained between both methods, experimental and computational. The static and total pressure values have a difference lower than $5 \%$. On the other hand, the velocity values are similar and have a similar trend with the increase of the mass flow rate. Therefore, the study of velocities inside a radial turbine volute demonstrate 
the capacity to measure experimentally the flow behaviour. Further, this work confirms a new method through a new tool using the experimental methodology to validate of any type of study related to the internal velocities in real turbines using CFD simulation.

Acknowledgments

Authors want to acknowledge the "Apoyo para la investigación y Desarrollo (PAID)" grant for doctoral studies (FPI-2018-S2-1368). The work has been partially supported by "Vicerrectorado de Investigación, Innovación y Transferencia UPV" through grant number PAID-06-2018.

\section{Bibliography}

[1] J. German, A. Isenstadt, M. Dorobantu, D. Boggs, and T. Watson, "Downsized, Boosted Gasoline Engines", Working paper 2016-21 International Council on Clean Transportation, 2016, pp. 1-23.

[2] H. Tang, A. Pennycott, S. Akehurst, and C. J. Brace, "A review of the application of variable geometry turbines to the downsized gasoline engine" Int. J. Engine Res., vol. 16, no. 6, pp. 810-825, 2015.

[3] M. Muqeem, M. Ahmad, and A. F. Sherwani, "Turbocharging of Diesel Engine for Improving Performance and Exhaust Emissions: A Review" IOSR J. Mech. Civ. Eng. Ver. III, vol. 12, no. 4, pp. 2278-1684, 2015.

[4] F. Payri, J. R. Serrano, P. Fajardo, M. A. Reyes-Belmonte, and R. Gozalbo-Belles, "A physically based methodology to extrapolate performance maps of radial turbines" Energy Convers. Manag., vol. 55, pp. 149-163, 2012.

[5] J. Macek and O. Vítek, "Simulation of pulsating flow unsteady operation of a turbocharger radial turbine" SAE Tech. Pap., no. 724, pp. 776-790, 2008.

[6] J. R. Serrano, P. Olmeda, A. Páez, and F. Vidal, "An experimental procedure to determine heat transfer properties of turbochargers" Meas. Sci. Technol., vol. 21, no. 3, 2010.

[7] P. Olmeda, V. Dolz, F. J. Arnau, and M. A. Reyes-Belmonte, "Determination of heat flows inside turbochargers by means of a one dimensional lumped model" Math. Comput. Model., vol. 57, no. 7-8, pp. 1847-1852, 2013.

[8] P. Olmeda, J. Serrano, A. Lefebvre, F. Arnau, and M. Reyes-Belmonte, "Importance of Heat Transfer Phenomena in Small Turbochargers for Passenger Car Applications" SAE Int. J. Engines, vol. 6, no. 2, pp. 716-728, 2013.

[9] D. Bohn, N. Moritz, and M. Wolff, "Conjugate flow and heat transfer investigation of a turbocharger: Part II - Experimental results" Turbo Expo 2003, vol. 3, pp. 1-7, 2003.

[10] J. R. Serrano, P. Olmeda, A. Tiseira, L. M. García-Cuevas, and A. Lefebvre, "Theoretical and experimental study of mechanical losses inautomotive turbochargers" Energy, vol. 55, pp. 888-898, 2013.

[11] J. R. Serrano, P. Olmeda, A. Tiseira, L. M. García-Cuevas, and A. Lefebvre, "Importance of Mechanical Losses Modeling in the Performance Prediction of Radial Turbochargers under Pulsating Flow Conditions" SAE Int. J. Engines, vol. 6, no. 2, pp. 1-10, 2013.

[12] J. Galindo, P. Fajardo, R. Navarro, and L. M. García-Cuevas, "Characterization of a radial turbocharger turbine in pulsating flow by means of CFD and its application to engine modeling" Appl. Energy, vol. 103, pp. 116-127, 2013.

[13] J. Galindo, S. Hoyas, P. Fajardo, and R. Navarro, "Set-up analysis and optimization of cfd simulations for radial turbines" Eng. Appl. Comput. Fluid Mech., vol. 7, no. 4, pp. 441- 
460, 2013.

[14] C. Zhu, W. Zhuge, Y. Zhang, and J. Peng, "Aerodynamic and Performance Behavior of a Radial Turbine at Design and Off-Design Conditions" no. January 2017, p. V01AT09A014, 2016.

[15] Y. Zhang and $\mathrm{Y}$. Wu, "A review of rotating stall in reversible pump turbine" Proc. Inst. Mech. Eng. Part C J. Mech. Eng. Sci., vol. 231, no. 7, pp. 1181-1204, 2017.

[16] C. Bell, D. Zimmerle, T. Bradley, D. Olsen, and P. Young, "Scalable turbocharger performance maps for dynamic state-based engine models" Int. J. Engine Res., vol. 17, no. 7, pp. 705-712, 2016.

[17] J. R. Serrano, F. J. Arnau, L. M. García-Cuevas, A. Dombrovsky, and H. Tartoussi, "Development and validation of a radial turbine efficiency and mass flow model at design and off-design conditions" Energy Convers. Manag., vol. 128, pp. 281-293, 2016.

[18] H. Schlichting, Boundary-layer theory, Seventh Ed. McGraw-Hill Book Company, 1979.

[19] F. R. Menter, "Two-equation eddy-viscosity turbulence models for engineering applications" AIAA J., vol. 32, no. 8, pp. 1598-1605, 2008.

[20] F. R. MENTER, "Influence of freestream values on k-omega turbulence model predictions" AIAA J., vol. 30, no. 6, pp. 1657-1659, Jun. 1992.

[21] D. C. WILCOX, "Reassessment of the scale-determining equation for advanced turbulence models" AIAA J., vol. 26, no. 11, pp. 1299-1310, Nov. 1988.

[22] F. R. Menter, R. Langtry, and T. Hansen, "CFD Simulation of Turbomachinery Flows Verification, Validation and Modelling" Eur. Congr. Comput. Methods Appl. Sci. Eng. ECCOMAS 2004, no. July, pp. 1-14, 2004.

[23] R. Pecnik, J. Witteveen, and G. laccarino, "Uncertainty Quantification for LaminarTurbulent Transition Prediction in RANS Turbomachinery Applications" no. January, 2014.

[24] A. T. Simpson, S. W. T. Spence, and J. K. Watterson, "A Comparison of the Flow Structures and Losses Within Vaned and Vaneless Stators for Radial Turbines" J. Turbomach., vol. 131, no. 3, p. 031010, 2009.

\section{Appendix I}

\section{Notation}

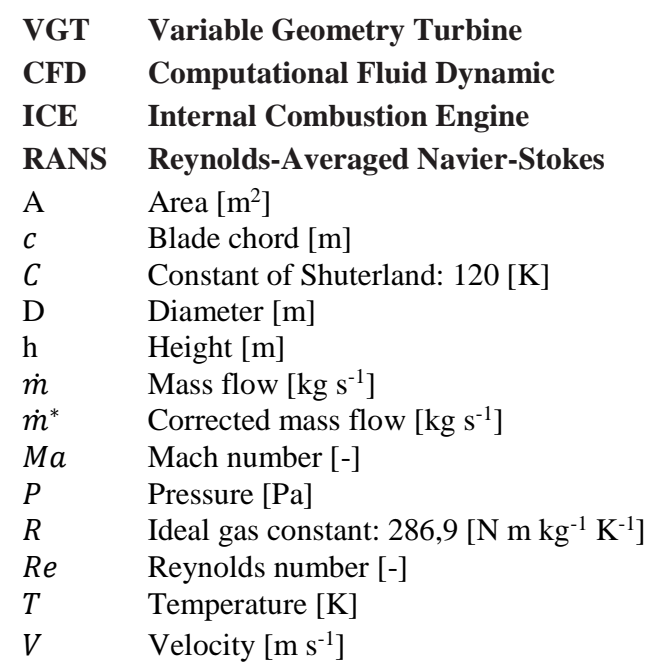

Greek symbols

$\gamma \quad$ Heat capacity ratio [-] 


$\begin{array}{ll}\epsilon & \text { Relative difference [\%] } \\ \mu & \text { Dynamic viscosity [N s m-2] } \\ \pi & \text { Pressure ratio [-] } \\ \rho & \text { Density [kg m-3] } \\ \varphi & \text { Generic variable }\end{array}$

\section{Subscripts}

0 Reference value

e Expansion

exp Experimental

ref Reference

rot Rotor

st Stator blades 